\title{
Time-temperature-transformation (TTT) diagram of dual-curable epoxy thermosets obtained via two sequential epoxy-amine condensations
}

\author{
Osman Konuray a , José M. Salla ${ }^{\text {a }}$, José M. Morancho a, Xavier Fernández-Francos a, Montserrat García-Alvarez ${ }^{\text {b }}$, \\ Xavier Ramis ${ }^{a}, *$ \\ a Thermodynamics Laboratory, ETSEIB Universitat Politècnica de Catalunya, Av. Diagonal 647, 08028, Barcelona, Spain \\ b Department of Chemical Engineering, ETSEIB Universitat Politècnica de Catalunya, Av. Diagonal 647, 08028, Barcelona, Spain
}

\section{A R T I C L E IN F O}

\section{Keywords:}

Epoxy

Diamine

Dual-curing

Thermosets

Time-transformation-temperature (TTT) dia-

gram

\begin{abstract}
A B S T R A C T
A simple and robust strategy to generate time-temperature-transformation (TTT) diagrams for dual-curable thermosets is presented. TTT diagram is built for a dual-curable amine-epoxy formulation. Both curing stages are epoxy-amine polycondensations. Whereas the first stage is carried out at relatively low temperature using a strongly nucleophilic aliphatic amine, the second is carried out at high temperature with a weakly nucleophilic aromatic amine. The good separation between curing stages enabled the individual kinetics analysis of each stage by integral isoconversional procedures. Gelation was determined by thermomechanical analysis; the glass transition temperature - conversion relationship was determined by calorimetry and was used to draw the vitrification line. Gelation and vitrification lines were checked by means of solubility tests and temperature modulated calorimetry. The results presented in the form of a TTT diagram showed the disparate reactivity of both curing stages and a substantial storage stability at the intermediate curing stage. These materials show great potential in applications where processing flexibility and intermediate stability are crucial.
\end{abstract}

\section{Introduction}

Dual curing is a methodology for obtaining thermosets by combining two different and compatible polymerization reactions. It provides great versatility and flexibility in product design and control of the curing. Among the different strategies used, a scheme based on two sequential click reactions is the most advantageous as it affords workable intermediate materials, which, upon exposure to a second stimulus, attain their ultimate properties without producing any by-products [1]. The control of the curing sequence is of paramount importance in this strategy and can be achieved by using a latent catalyst or by different stimuli at each stage or when the reaction rates are disparate [2-6]. TTT cure diagram plays a pivotal role in knowing the properties of thermosets and the physical events (gelation and vitrification) that take place during curing [7-11]. In dual-curable thermosets, this diagram also informs about the storage stability of the intermediate materials, the conditions of safe storage and about the curing stage in which gelification is achieved. As a consequence, the potential applications of the intermediate and final materials can be deducted from the TTT diagram [12].

\footnotetext{
* Corresponding author.

Email address: ramis@mmt.upc.edu (X. Ramis)
}

There are many methodologies described for the construction of the TTT diagram, some of which are contradictory and in many cases not comparable. The main problems are: a) the definition and determination of the gel point, b) the necessity to extrapolate experimental kinetic data in order to build the whole diagram and c) the necessity to mix data obtained from different techniques, which enforces the assumption that a material cures at the same rate in all equipments. This approach can in some cases be a source of error, since the reaction rate, especially in autocatalytic curings, depends strongly on the sample mass and geometry, on the holder in which the sample is placed and on the way heat is transmitted [13]. As a consequence, additional experimental data must be collected to verify the assumptions made for the construction of the TTT diagram and their range of applicability ().

In a previous manuscript [6] we developed a new family of dual-curable epoxy thermosets, consisting of two consecutive amine-epoxy polycondensations at different temperatures and using different diamines: one aliphatic, the other aromatic, each with a different nucleophilic character. Intermediate materials had remarkable stabilities at room temperature, thanks to the low reactivity of the aromatic amine used as stage 2 curing agent, and also to vitrification during the first 


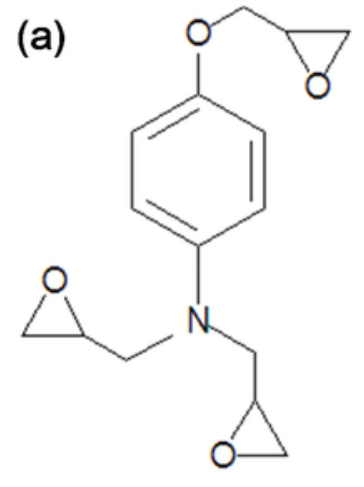<smiles>CC(N)COCC(C)N</smiles>

(c)

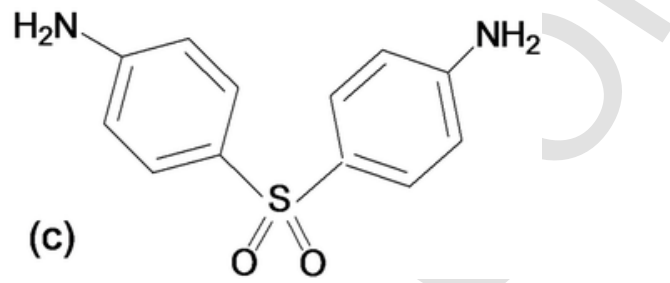

Scheme 1. Molecular structures of the chemicals used: (a) TGAP, (b) JEF with $n=6$ and (c) DDS

curing stage or during storage. The materials ranged from ungelled liquids (suitable as adhesives) to highly crosslinked solids (shape-memory materials or structural composites).

The purpose of this work is four-fold: a) to study reaction kinetics and the physical events that take place during curing of a dual-curable epoxy thermosets obtained via two sequential epoxy-amine condensations, b) to show the results in the form of TTT diagrams that can be used to establish the optimum conditions for curing, c) to illustrate the main differences between dual-curing and conventional curing systems in terms of flexibility of the curing process and d) to establish a methodology generally applicable for the curing of any thermoset using a minimum amount of experimental data, with maximum reliability.

The kinetics of conventional and dual curing was analyzed by differential scanning calorimetry (DSC) using isoconversional integral isothermal and non-isothermal procedures. Curing kinetics were also analyzed using model-fitting methods and autocatalytic kinetic models. $T_{g}$ 's of uncured, intermediate and final materials were determined by calorimetry. The relationship between glass transition temperature $\left(T_{g}\right)$ and degree of conversion $(\alpha)$ was also determined and compared with the theoretical one. Vitrification was determined by simulation using the isoconversional kinetic parameters and the relationship $T_{g^{-}} \alpha$, assuming that the material vitrifies when its $T_{g}$ reaches the curing temperature. Gelation during curing was determined by isothermal DSC and thermomechanical analysis (TMA) combined experiments. Vitrification times were checked experimentally by temperature modulated DSC (TMDSC) and the gelation data through solubility tests. The TTT diagram was used to illustrate the main transformations taking place during curing, the dual nature of the curing, the intermediate storage stability and consequently the enhanced applicability of dual curing systems in comparison with conventional ones.

\section{Experimental methods}

\subsection{Materials}

The tri-glycidyl p-aminophenol epoxy resin (TGAP hereafter) with trade name Araldite MY0510 (Huntsman Advanced Materials) and an epoxy equivalent $95 \mathrm{~g} /$ ee determined following standard procedures [6], was used after dried in vacuum. As hardener, 4,4-diamino diphenyl sulphone (DDS hereafter) and poly(propylene glycol) bis(2-aminopropyl ether) (Jeffamine, $M_{w}=400 \mathrm{~g} / \mathrm{mol}$ ) (JEF hereafter), both supplied by Sigma-Aldrich were used as received (Scheme 1).

\subsection{Sample preparation}

Samples were prepared in 1-2 gr batches inside $5 \mathrm{ml}$ vials using the following procedure: DDS was weighed and added to TGAP and was kept under magnetic stirring agitation at $90^{\circ} \mathrm{C}$ for $5-10 \mathrm{~min}$ until the solution became clear. The mixture was left to cool down to room temperature after which the required amount of JEF was added, quickly stirred and immediately sent to analysis or sample preparation. Neat TGAP-JEF formulation was prepared mixing both components directly at room temperature. We studied a dual formulation coded as TGAPJEF50DDS50 (which contains 100 epoxy, $50 \mathrm{JEF}$, and 50 DDS equivalents and stage 1 and stage 2 wt fractions of $55.4 \%$ and 44.6 , respectively). This formulation was selected based on our previous results [6] and because it contains the same equivalent amount of both amines, being the most representative of dual curing strategy. For comparison purposes, the curing kinetics of both neat formulations (coded as TGAPJEF and TGAPDDS) were also studied. In all formulations, ratio of epoxy to amine hydrogen equivalents was 1:1.

\subsection{Experimental techniques}

Calorimetric analyses of materials were carried out on a Mettler DSC822e thermal analyzer calibrated using an indium standard (heat flow calibration) and used to determine reaction heats and glass transition temperatures $\left(T_{g}\right)$. Samples of $10 \mathrm{mg}( \pm 0.1 \mathrm{mg}$ ) were placed in aluminium pans and were scanned under $\mathrm{N}_{2}$ atmosphere in the analyzer using various temperature programs depending on the type of measurement. Isothermal curing was performed at temperatures of 70, 80, 90 and $100^{\circ} \mathrm{C}$ (stage 1 ) and $150,160,170$ and $180^{\circ} \mathrm{C}$ (stage 2) and non-isothermal curing was performed at $1,2,5$ and $10^{\circ} \mathrm{C} / \mathrm{min}$ up to $300^{\circ} \mathrm{C}$ for the dual curing or the second curing process after a first stage curing at $90^{\circ} \mathrm{C}$ for $180 \mathrm{~min}$. The conversion of epoxy groups was calculated as follows:

$\alpha=\frac{\Delta h_{t, T}}{\Delta h_{t o t}}$

where $\Delta h_{t, T}$ is the heat evolved up to a time $t$ or a temperature $T$ during isothermal and dynamic curing experiments, respectively and $\Delta h_{\text {tot }}$ is the total heat released during curing. In determination of absolute conversion, $\Delta h_{\text {tot }}$ was the total heat obtained dynamically, whereas in determination of relative conversion, $\Delta h_{\text {tot }}$ was taken as the total heat released during either stage 1 or 2 . In our dual formulation, relative conversion is simply twice the absolute since equal moles of amine react at each stage. 
The $T_{g}$ of the uncured $\left(T_{g 0}\right)$, intermediate $\left(T_{\text {gint }}\right)$ (cured $180 \mathrm{~min}$ at $90^{\circ} \mathrm{C}$ ) and final $\left(T_{g_{\infty}}\right)$ (intermediate postcured $180 \mathrm{~min}$ at $180^{\circ} \mathrm{C}$ ) materials were determined from a scan at $10^{\circ} \mathrm{C} / \mathrm{min}$ and the error estimated as $\pm 1{ }^{\circ} \mathrm{C}$. The $T_{g}$ was determined as the midpoint in the heat capacity step during the glass transition. The increase in heat capacity during glass transition, $\Delta C_{P}$, was also determined. The DIN 51007 method, included in the STARe software by Mettler, was used for these determinations. The isothermal curing times were selected by means of simulations using isoconversional data and were sufficiently long to complete each curing stage [6].

The relationship between the conversion and the glass transition temperature, $T_{g}-\alpha$, was determined from partially cured samples, subsequently heated up at $10^{\circ} \mathrm{C} / \mathrm{min}$ to determine their $T_{g}$ and the residual heat $\Delta h_{r e s}$. Conversion of partially cured samples was determined as:

$\alpha=1-\frac{\Delta h_{\text {res }}}{\Delta h_{\text {tot }}}$

Vitrification times were determined by temperature modulated DSC (TMDSC) conducted at a single fixed frequency. Samples of approximately $20 \mathrm{mg}$ were quasi-isothermally cured at different temperatures using temperature amplitude of $0.5 \mathrm{~K}$, with modulation periods of $60 \mathrm{~s}$. Fig. 1 shows, as an example, the complex capacity as a function of time for quasi-isothermal curing of TGAPDDS formulation at $140^{\circ} \mathrm{C}$. As can be seen, the drop in complex heat capacity is characterized by three different time points: onset $\left(t_{v, o}\right)$, midpoint $\left(t_{v, \text { mp }}\right)$, and endset $\left(t_{v, \text { end }}\right)$. The vitrification times were taken as the endset because of its excellent agreement with a different approximation of the vitrification time. The details of this latter approximation will be presented in the following sections.

A Mettler thermo-mechanical analyzer SDTA840 was used to determine the gel point. A silanized glass fiber disc about $5 \mathrm{~mm}$ in diameter was impregnated with the liquid (uncured) formulation and sandwiched between two aluminium discs. Samples were placed at 70, 80, 90 and $100^{\circ} \mathrm{C}$ for different times and subjected to an oscillatory force from 0.005 to $0.1 \mathrm{~N}$ with an oscillation frequency of $0.083 \mathrm{~Hz}$. The gel time, $t_{g e l}$, was taken as the onset in the decrease of the oscillation amplitude measured by the probe or equivalently as the onset of the amplitude-time curve when the material is transformed from a liquid state to a solid state during gelation. The conversion of epoxy groups at the gel point, $\alpha_{\text {gel }}$, was determined as the conversion reached isothermally in the DSC at the gel time. Fig. 2 shows, as an example, the gelification of TGAPJEF50DDS50 formulation at $70^{\circ} \mathrm{C}$ in TMA analyzer and the gel point determination.

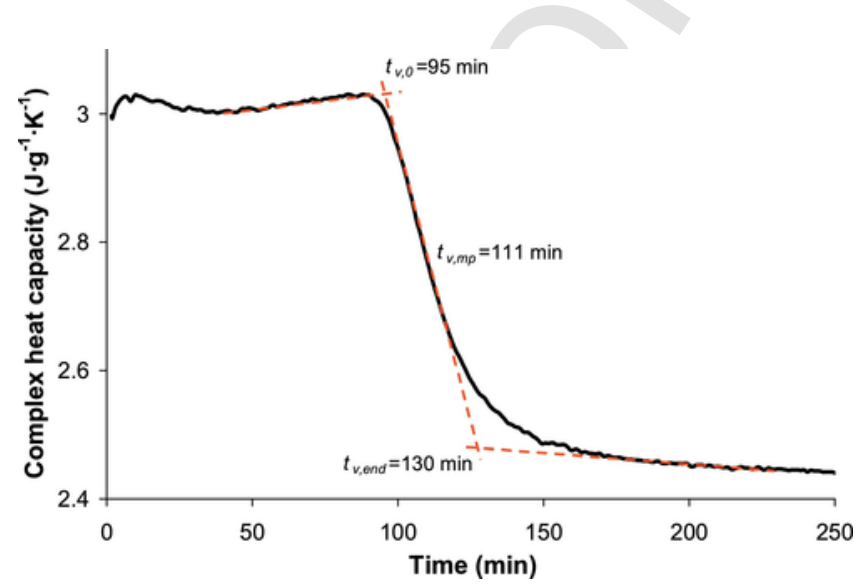

Fig. 1. Complex heat capacity. $C_{P}{ }^{*}$, as a function of time for TMDSC for quasi-isothermal curing of TGAPDDS formulation at $140^{\circ} \mathrm{C}$ with a modulation period of $60 \mathrm{~s}$ and a temperature amplitude of $0.5 \mathrm{~K}$. The determination of the extrapolated onset $\left(t_{v, 0}\right)$, midpoint $\left(t_{v, m p}\right)$ and extrapolated endset $\left(t_{v, \text { end }}\right)$ vitrifaction times are also shown.

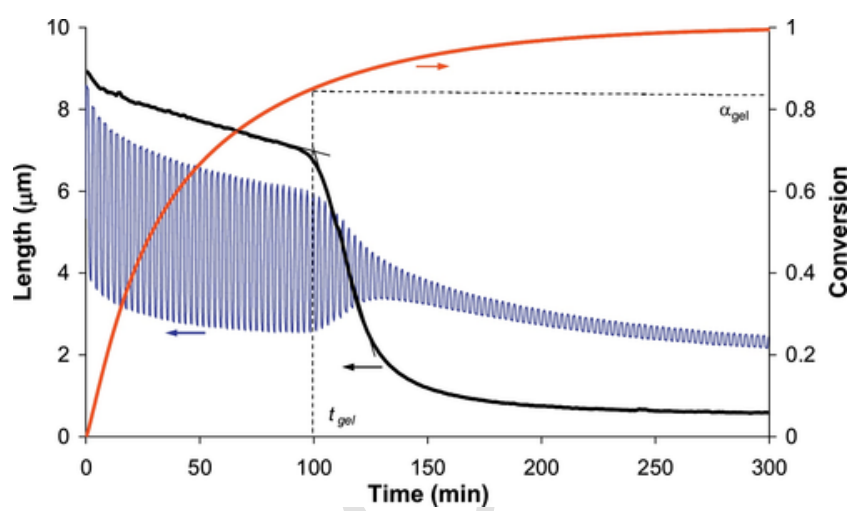

Fig. 2. Determination of gel point conversion by combination of TMA oscillatory (blue) and DSC (red) measurements, corresponding to formulation TGAPJEF50DDS50 cured at $70^{\circ} \mathrm{C}$. TMA amplitude is also plotted (black). (For interpretation of the references to colour in this figure legend, the reader is referred to the web version of this article.)

The theoretical conversion of epoxy groups at the gel point, $\alpha_{g e l}$ , during epoxy-amine condensation (stage 1) was calculated assuming ideal random step-wise reaction, using the well-known Flory-Stockmayer equation $[14,15]$ :

$\alpha_{g e l}^{\text {theor }}=\frac{1}{\sqrt{r(f-1)(g-1)}}$

for TGAPJEF50DDS50, formulation $r=2$ is the epoxy/hydrogen amine equivalent ratio, $f=3$ the epoxy monomer functionality and $g=4$ the amine functionality.

\section{Theoretical}

\subsection{Kinetic analysis}

The kinetic methodology follows the ICTAC Kinetics Committee recommendations [16] and the results obtained in previous works $[12,17-20]$. Our goal is to establish a kinetic methodology as simple as possible and that it allows building TTT diagrams easily and reliably.

Most kinetic parameters were determined using isoconversional methods which are based on the assumption that reaction rate at constant conversion is only a function of temperature.

Considering that the reaction rate $\mathrm{d} \alpha \mathrm{d} t$ is a function of temperature and extent of conversion and that the dependence of the rate constant $k$ on the temperature follows Arrhenius equation, the reaction kinetics can be described as:

$\frac{d \alpha}{d t}=k f(\alpha)=A \exp \left(-\frac{E}{R T}\right) f(\alpha)$

where $f(\alpha)$ the differential conversion function, $R$ the gas constant, $A$ the pre-exponential factor and $E$ the activation energy.

Under isothermal conditions, the integration of Eq. (4) and taking natural logarithms, leads to the following expression:

$\ln t_{\alpha, i}=\ln \left[\frac{g(\alpha)}{A_{\alpha}}\right]+\frac{E_{\alpha}}{R T_{i}}$

where $g(\alpha)$ is the integral conversion function given as

$g(\alpha)=\int_{0}^{\alpha} \frac{d \alpha}{f(\alpha)}=A \int_{0}^{t} \exp \left(-\frac{E}{R T}\right) d t$

and $t_{\alpha, i}$ is the time to reach a given extent of conversion at different 
temperatures $T_{i}$. The values of kinetic parameters $E_{\alpha}$ and $\ln \left[g(\alpha) / A_{\alpha}\right]$, are determined from the slope and intercept at the origin of the plot $\ln$ $t_{\alpha, i}$ versus $1 / R T_{i}$, respectively. If the reaction model $g(\alpha)$ is known, the corresponding pre-exponential factor can be calculated for each conversion.

For the commonly used constant heating rate program, the so-called temperature integral, does not have an analytical solution. There are a number of integral isoconversional methods that differ in approximations of the temperature integral. We selected the Kissinger-Akahira-Sunose (KAS) equation [21]:

$\ln \left(\frac{\beta_{i}}{T_{\alpha, i}^{2}}\right)=\ln \left[\frac{A_{\alpha} R}{g(\alpha) E_{\alpha}}\right]-\frac{E_{\alpha}}{R T_{\alpha}}$

This equation is obtained using the Murray and White approximation [16] or the Coats-Redfern approximation [22] to solve the temperature integral and considering that $2 R T_{i} / E_{\alpha}$ is much lower than 1 . Although one could use more complex approximations of the temperature integral for the sake of better accuracy, the simple Eq. (6) is fairly adequate for the purpose of the current analysis [16].

The values of dynamic kinetic parameters $E_{\alpha}$ and $\ln \left[A_{\alpha} R / g(\alpha) E_{\alpha}\right]$, are determined from the slope and intercept at the origin of the plot $\ln \left(\beta_{i} / T_{\alpha, i}{ }^{2}\right)$ versus $T_{\alpha}{ }^{-1}$, respectively. Again, if the reaction model $g(\alpha)$ is known, the corresponding pre-exponential factor can be calculated for each conversion. The kinetic parameters of Eqs. (5) and (6) are directly related, so it is possible to simulate isothermal curing based on non-isothermal data without knowing $g(\alpha)$ as long as the curing process is the same in both conditions. In this work, the isothermal reaction times of stage 2 were simulated until the point of vitrification so that the reactions could be safely assumed kinetically controlled rather than diffusion controlled.

In this work, the sequentiality of the dual curing allows studying the kinetics of each curing stage individually. The kinetics of first curing stage of TGAPJEF50DDS50 formulation was determined isothermally by using Eq. (5), but the second curing stage was analysed dynamically by using Eq. (6), after first stage was completed in isothermal conditions at $90^{\circ} \mathrm{C}$ for $180 \mathrm{~min}$. In a previous work, it was demonstrated by FTIR and DSC that TGAPJEFDDS mixtures achieve first stage cure in these conditions [6]. Second stage was studied in isothermal conditions as well, but the results (not shown here), were not sufficiently precise due to difficulty in detecting the isothermal heat at the start and end of curing. In these experiments, a significant degree of conversion had already been reached before the isothermal regime set in. The curing kinetics of neat TGAPJEF and TGAPDDS formulations were studied dynamically by using KAS equation.

To determine the reaction model, linear model fitting methods were used, since isoconversional activation energy was quasi-constant throughout the conversion range, as commonly observed in single-step processes $[16,23]$. On the basis of the integral composite method, that presupposes one single set of activation parameters for all conversions and heating rates, the kinetic model of nonisothermal curing was determined, using Eq. (6) rearranged as:

$\ln \left(\frac{g(\alpha) \beta}{T^{2}}\right)=\ln \left[\frac{A R}{E}\right]-\frac{E}{R T}$

Representation of $\ln \left(g(\alpha) \beta_{i} / T^{2}\right)$ against $-(R T)^{-1}$ throughout the whole conversion range and for all the heating rates should produce a single straight line with a slope $E$ equal to the isoconversional activation energy, if the kinetic model $g(\alpha)$ is right. The preexponential factor $A$ is determined from the intercept at the origin. Given that the curing of epoxy-amine systems is autocatalytic, the experimental data was fitted to an autocatalytic kinetic model with $n+m=2$, where $n$ and $m$ are the partial orders of reaction [20,24,25]. Eqs. (8) and (9) show $f(\alpha)$ and $g(\alpha)$ functions, respectively, for the autocatalytic kinetic model used. Eq. (9) can be obtained by direct integration of Eq. (8) rearranged with $n+m=2$ (the kinetic model used in this work). $g(\alpha)$ can also be written in terms of $n$ by replacing $m$ by $2-n$ in:

$f(\alpha)=\alpha^{m}(1-\alpha)^{n}$

$g(\alpha)=\frac{1}{1-m}\left(\frac{\alpha}{1-\alpha}\right)^{1-m}=\frac{1}{n-1}\left[\frac{(1-\alpha)}{\alpha}\right]^{1-n}$

Details of the model fitting methodology used can be found in a previous work [20].

Although there are more complex autocatalytic models used to describe the curing of epoxy-amine or epoxy-anhydride systems especially when diffusion control takes effect [26-30], the model described in Eqs. (8) and (9) satisfactorily affords an average value of the pre-exponential factor and the rate constant.

A similar methodology was used for the determination of the kinetic model from isothermal curing experiments. Rearrangement of Eq. (5) leads to the following Eq. (10):

$\ln \frac{t}{g(\alpha)}=\ln \left[\frac{1}{A}\right]+\frac{E}{R T}$

Representation of $\ln (t / g(\alpha))$ against $(R T)^{-1}$ throughout the whole conversion range and for all the isothermal temperatures should produce a single straight line with a slope $E$ equal to the isoconversional activation energy, if the kinetic model $g(\alpha)$ is right. It should be mentioned that all the data points should be compiled in four groups corresponding to the four curing temperatures used.

\subsection{Construction of TTT diagram}

In this work we use a simple methodology to build TTT diagrams using only calorimetric data obtained by DSC and TMA tests (or other alternative gelation determination methods) with only a few experiments, following a similar procedure reported previously [13]. The minimum experiments required are:

(1) Four isothermal curing experiments in DSC to determine the kinetics and draw the isoconverional lines (including gelation). Depending on the quality of data, non-isothermal experiments can be more suitable.

(2) An isothermal curing in TMA to obtain the gelation time, $t_{\text {gel }}$. Using $t_{g e l}$ and the conversion-time curve obtained previously by DSC, $\alpha_{g e l}$ is estimated. Determination of gel point can be performed with other techniques, such as the solubility test. If the curing process is an ideal random step-wise reaction, $\alpha_{\text {gel }}$ can be determined theoretically using the Flory-Stockmayer equation, given the composition and the functionalities of the monomers.

(3) A dynamic curing and postcuring in DSC to obtain $T_{g o}, T_{g \infty}, \Delta C_{p o}$, and $\Delta C_{p \infty}$ which would then be used to obtain the $T_{g}-\alpha$ relationship by using Dibenedetto equation. Vitrification line is drawn using the $T_{g}-\alpha$ relationship and by extrapolating isoconversional lines up to $T_{g}=T_{c}$. $T_{g}-\alpha$ relationship can be verified experimentally from partial curing experiments, and vitrification times extrapolated this way can be compared with those determined using techniques such as TMDSC.

With regard to dual curing systems, a double set of curing experiments should be performed in order to establish the kinetics and vitrification of the two curing stages [12]. 


\section{Results and discussion}

\subsection{Kinetic analysis}

\subsubsection{Neat TGAPJEF and TGAPDDS formulations}

First of all, the kinetics of dynamic curing of the neat formulations TGAPJEF and TGAPDDS was studied. Although some studies deal with the curing kinetics of TGAPDDS systems [31,32], there are no published works on the curing of TGAPJEF. In a previous manuscript, the different reactivity of each amine, namely JEF and DDS, was established but their curing kinetics were not studied [6]. Due to the fact that TGAPDDS has a very high $T_{g}\left(235^{\circ} \mathrm{C}\right)$ [6], the kinetics was studied dynamically to avoid the occurrence of vitrification during isothermal curing.

Fig. 3a and $\mathrm{b}$ show the DSC traces and conversion-temperature plots of TGAPJEF and TGAPDDS formulations cured dynamically at different heating rates. As it is expected, the curves shift to higher temperatures on increasing the heating rate. It is also clearly observed that formulations containing JEF react at relatively low temperatures, whereas DDS formulations react at temperatures above $140^{\circ} \mathrm{C}$. The significantly different reactivity of JEF and DDS, more evident at low heating rates, hints the suitability of a TGAP, JEF and DDS mixture as a dual-curable system.

An average reaction heat of $524 \mathrm{~J} / \mathrm{g}(102 \mathrm{~kJ} / \mathrm{ee})$ and $629 \mathrm{~J} / \mathrm{g}(99 \mathrm{~kJ} /$ ee) was detected for TGAPJEFF and TGAPDDS formulations, respectively. The similarity between enthalpies per epoxy equivalent, and the reported data for other similar epoxy systems as approximately
$100 \mathrm{~kJ} / \mathrm{ee}[3,33]$, confirms that both formulations were completely cured.

From the data shown in Fig. 3b the kinetic of curing was established using Eq. (6) (isoconversional analysis) and Eqs. (7)-(9) with autocatalytic model with $n+m=2$ (linear model fitting method). Tables 1 and 2 show the results obtained for TGAPJEF and TGAPDDS formulations, respectively.

The activation energy obtained by KAS method of both formulations remains virtually constant in the $0.2-0.8$ conversion range, as is generally reported in other works $[9,12,34]$. In general, this result suggests that the reaction mechanism is the same in this range of conversion and only a single kinetic model is needed to describe this process. The activation energy of TGAPJEF, around $50 \mathrm{~kJ} / \mathrm{mol}$, decreases slightly with increasing degree of conversion, following the same trend observed for DGEBA-JEF formulations [12] or other aliphatic amines [9]. This can be interpreted in terms of the lower activation energy of hydroxyl-catalyzed epoxy-amine condensation $[35,36]$, that is, its autocatalytic component [37], which increases its contribution as the curing process advances. It can be observed that the isoconversional activation energy of TGAPDDS is higher than that of TGAPJEF, in agreement with the higher curing temperatures observed in Fig. 3. The activation energy of TGAPDDS is similar to that reported for the curing of DGEBA-DDS [38] and TGDDM-DDS [27]. The increase in activation energy observed at the end of the curing process can be related to vitrification taking place during curing at the lower heating rates because of the high $T_{g}$ of the TGAPDDS system, as suggested by the end behaviour of the dashed conversion curves at 1 and $2{ }^{\circ} \mathrm{C} / \mathrm{min}$ in Fig. $3 \mathrm{~b}$ and as commonly reported in the literature $[9,39]$.

Although activation energy reflects the reactivity of the systems studied, in many reactions it is better to discuss the rate constant $(k)$ or
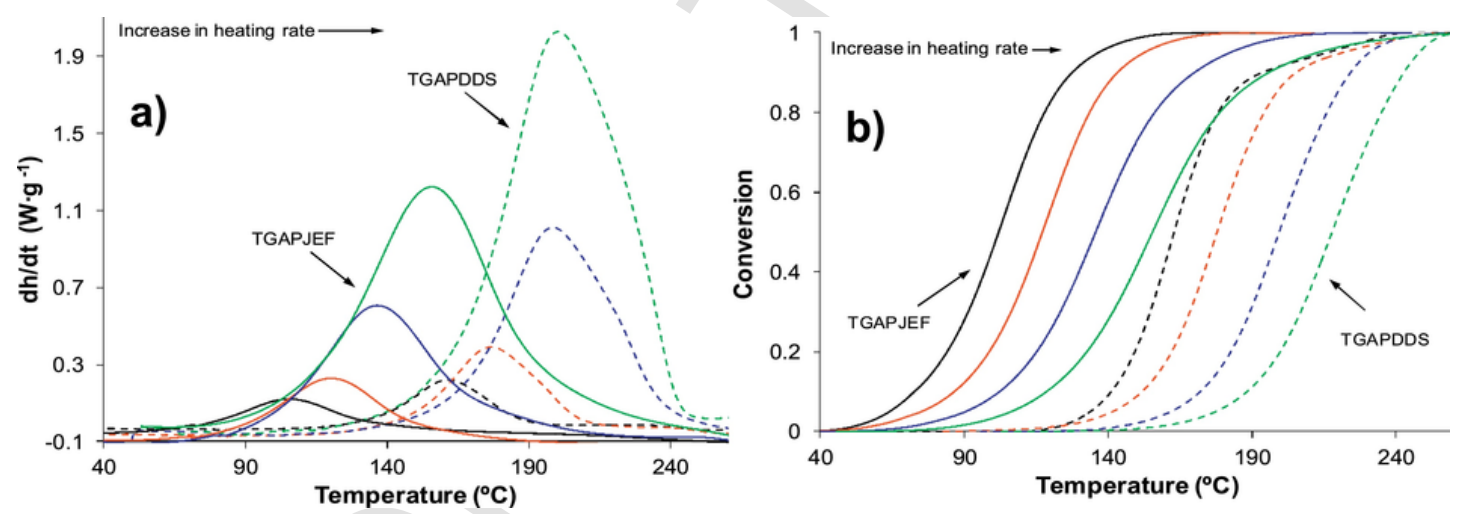

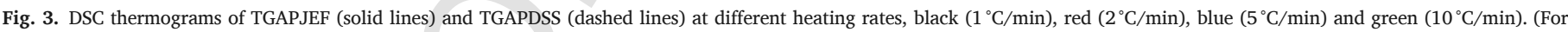
interpretation of the references to colour in this figure legend, the reader is referred to the web version of this article.)

Table 1

Kinetic parameters determined by isoconversional integral (top) and model fitting analysis (bottom) of the dynamic curing of TGAPJEF.

\begin{tabular}{|c|c|c|c|c|c|c|c|}
\hline$\alpha$ & $E(\mathrm{~kJ} / \mathrm{mol})$ & $\ln \left[\frac{A R}{g(\alpha) E}\right]\left(\mathrm{min}^{-1}\right)$ & $\ln \left[\frac{g(\alpha)}{A}\right](\min )$ & $r^{\mathrm{a}}$ & $\ln A^{\mathrm{b}}\left(\min ^{-1}\right)$ & 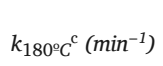 & $\left(\frac{d_{\alpha}}{d t}\right)_{180^{\circ} C}^{\mathrm{c}}\left(\min ^{-1}\right)$ \\
\hline 0.1 & 51 & 6.10 & -14.82 & 0.9986 & 13.96 & 1.455 & 0.5054 \\
\hline 0.2 & 52 & 5.65 & -14.38 & 0.9984 & 14.02 & 1.336 & 0.5013 \\
\hline 0.3 & 52 & 5.34 & -14.08 & 0.9984 & 14.05 & 1.294 & 0.4573 \\
\hline 0.4 & 52 & 5.05 & -13.79 & 0.9985 & 14.03 & 1.273 & 0.3919 \\
\hline 0.5 & 52 & 4.73 & -13.47 & 0.9986 & 13.95 & 1.257 & 0.3143 \\
\hline 0.6 & 51 & 4.35 & -13.08 & 0.9987 & 13.82 & 1.242 & 0.2325 \\
\hline 0.7 & 50 & 3.87 & -12.58 & 0.9989 & 13.59 & 1.225 & 0.1528 \\
\hline 0.8 & 49 & 3.12 & -11.80 & 0.9989 & 13.14 & 1.186 & 0.0810 \\
\hline 0.9 & 45 & 1.64 & -10.24 & 0.9980 & 12.08 & 1.088 & 0.0254 \\
\hline$n$ & $m$ & $E(\mathrm{~kJ} / \mathrm{mol})$ & & $\ln A(\mathrm{~m}$ & & $r$ & \\
\hline 1.61 & 0.39 & 51 & & 13.62 & & 0.9977 & \\
\hline
\end{tabular}

a Linear regression coefficient.

b Pre-exponential factor determined by using the isoconversional parameters and the autocatalytic model.

c Rate constant and reaction rate determined at $180^{\circ} \mathrm{C}$ by using Arrhenius equation and Eq. (4). 
Table 2

Kinetic parameters determined by isoconversional integral (top) and model fitting analysis (bottom) of the dynamic curing of TGAPDDS.

\begin{tabular}{|c|c|c|c|c|c|c|c|}
\hline$\alpha$ & $E(\mathrm{~kJ} / \mathrm{mol})$ & $\ln \left[\frac{A R}{g(\alpha) E}\right]\left(\min ^{-1}\right)$ & $\ln \left[\frac{g(\alpha)}{A}\right](\min )$ & $r^{\mathrm{a}}$ & $\ln A^{\mathrm{b}}\left(\min ^{-1}\right)$ & $k_{180^{\circ} C^{c}}\left(m^{-1}\right)$ & $\left(\frac{d_{\alpha}}{d t}\right)_{180^{\circ} C}{ }^{\mathrm{c}}\left(\mathrm{min}^{-1}\right)$ \\
\hline 0.1 & 69 & 8.00 & -17.02 & 0.9977 & 16.57 & 0.184 & 0.0508 \\
\hline 0.2 & 68 & 7.25 & -16.26 & 0.9994 & 16.23 & 0.170 & 0.0551 \\
\hline 0.3 & 67 & 6.84 & -15.84 & 0.9997 & 16.08 & 0.167 & 0.0540 \\
\hline 0.4 & 67 & 6.55 & -15.55 & 0.9999 & 16.01 & 0.167 & 0.0494 \\
\hline 0.5 & 67 & 6.32 & -15.31 & 0.9999 & 15.98 & 0.169 & 0.0423 \\
\hline 0.6 & 67 & 6.13 & -15.12 & 0.9999 & 16.00 & 0.171 & 0.0333 \\
\hline 0.7 & 67 & 6.04 & -15.04 & 0.9999 & 16.15 & 0.173 & 0.0236 \\
\hline 0.8 & 69 & 6.31 & -15.34 & 0.9999 & 16.72 & 0.177 & 0.0139 \\
\hline 0.9 & 85 & 9.62 & -18.85 & 0.9978 & 20.64 & 0.158 & 0.0046 \\
\hline$n$ & $m$ & $E(\mathrm{~kJ} / \mathrm{mol})$ & & $\ln A(\mathrm{~m}$ & & $r$ & \\
\hline 1.51 & 0.49 & 68 & & 16.45 & & 0.9986 & \\
\hline
\end{tabular}

a Linear regression coefficient.

b Pre-exponential factor determined by using the isoconversional parameters and the autocatalytic model.

c Rate constant and reaction rate determined at $180^{\circ} \mathrm{C}$ by using Arrhenius equation and Eq. (4).

the reaction rate $(\mathrm{d} \alpha / \mathrm{d} t)$, due to the compensation effect between the activation energy and the pre-exponential factor [40]. In JEF formulations, they attain values 5-10 times larger than in DDS formulations. This large difference can be attributed to the different nucleophilic character of each amine. The weak nucleophilic character of DDS, which is due to the delocalization by resonance of the nitrogen lone pair of electrons, allows the sequential curing of formulations containing JEF and DDS, as will be shown later.

The two systems show similar kinetic models as expected since both processes are epoxy-amine condensations. The linear regression coefficients and the similarity between isoconversional and model fitted activation energies demonstrate the quality of the fitting. Although the model fitting parameters are similar for both formulations, the autocatalytic parameter $m$ is slightly higher when DDS is used. The larger amount of hydroxyl groups formed during curing of TGAPDDS exert a higher catalytic effect, once the reaction starts. It must be taken into account that DDS and JEF have hydrogen amine equivalents of $62.1 \mathrm{~g} / \mathrm{eH}$ and $100 \mathrm{~g} / \mathrm{eH}$, respectively. Moreover, the polyether structures of JEF tend to form unreactive complexes that decrease the autocatalytic behaviour of TGAPJEF formulation [41].

\subsubsection{TGAPJEF50DDS50 dual formulation}

First of all the dynamic curing of TGAPJEF50DDS50 formulation was studied and compared with that of TGAPJEF and TGAPDDS neat formulations. Fig. 4 shows the sequential character of the curing process of TGAPJEF50DDS50. Two peaks are observed, the first and second of which are associated to TGAPJEF condensation and to

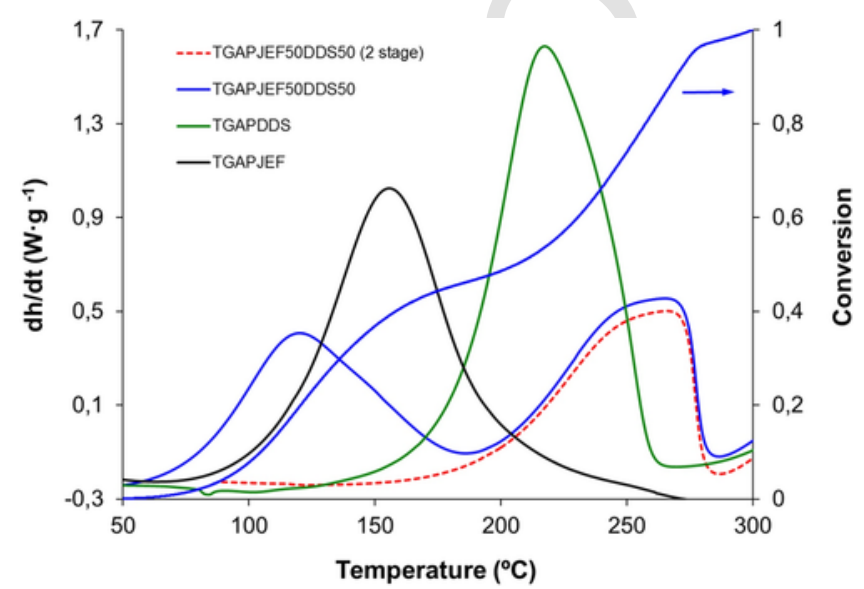

Fig. 4. DSC thermograms at $10^{\circ} \mathrm{C} / \mathrm{min}$ of TGAPJEF (neat), TGAPDSS (neat), TGAPJEF50DDS50 (dual) and TGAPJEF50DDS50 after $180 \mathrm{~min}$ at $90^{\circ} \mathrm{C}$ (dual, stage 2).
TGAPDDS condensation, respectively. The conversion-temperature curve shows that the conversion at each stage practically agrees with the composition of the formulation. The curing of the TGAPJEF50DDS50 formulation was considered complete since a total reaction heat of $568 \mathrm{~J} / \mathrm{g}(100 \mathrm{~kJ} / \mathrm{ee})$ was released.

With regard to the neat formulations, Fig. 4 shows that stage 1 and stage 2 of the dual formulation are shifted to lower and higher temperatures, respectively. The dilution of DDS in the formulation and the inhibiting effect of the polyether structure of JEF on the amine-epoxy nucleophilic addition $[6,41]$ are the culprits of the deceleration of stage 2 . On the contrary, the acceleration observed at stage 1 can be explained in terms of the decreasing negative impact of polyether structures on reactivity, in spite of the dilution of amine groups of JEF that would tend to decrease the curing rate. Furthermore, a slight catalytic contribution of the increased concentration of tertiary amine groups (coming from TGAP) cannot be discarded. The catalytic (stage 1) and inhibitive (stage 2) effects observed in TGAPJEF50DDS50, enhance the sequential character of the formulations, reducing the possible overlap between curing stages. In a previous work [6], it was demonstrated that the first curing stage is complete after $180 \mathrm{~min}$ at $90^{\circ} \mathrm{C}$ and no DDS reacts during this period. Moreover, the intermediate materials obtained after stage 1 exhibited a significant storage stability. Fig. 4 confirms this finding, since the residual DSC peak after first curing stage is identical with the second peak in the dual formulation. A reaction heat of $49 \mathrm{~kJ} / \mathrm{ee}$ and of $100 \mathrm{~kJ} /$ ee were respectively measured during stage 2 (after stage 1 ) and dual curing, indicating that exactly half the epoxy groups react in each stage.

Although the kinetics of dynamic curing of the dual formulation was studied (results not shown) and used to estimate the isothermal reaction times, due to the slight overlap observed between stages (Fig. 4) it was decided to study each curing stage separately. Stage 1 was studied isothermally at $70,80,90$ and $100{ }^{\circ} \mathrm{C}$ for curing times sufficiently long to ensure completion of stage 1 , and without triggering stage 2. Fig. 5 shows the conversion and calorimetric curves corresponding to stage 1 of TGAPJEF50DDS50 at different temperatures. The evolution of these curves with temperature follows the expected trends, shifting to longer times on increasing the temperature. The rate curves show the expected autocatalytic character for an epoxy-amine formulation. An average reaction heat of $47 \mathrm{~kJ} /$ ee was detected during isothermal curing, indicative again that stage 1 is practically complete, leaving stage 2 intact.

The kinetics of isothermal curing of stage 1 was studied by using isoconversional and model fitting analysis (Eqs. (5), (8), (9) and (10)) and Table 3 shows the results obtained. Activation energy is practically constant throughout the curing and similar to that obtained by model fitting. These results, along with the values of the regression coeffi- 


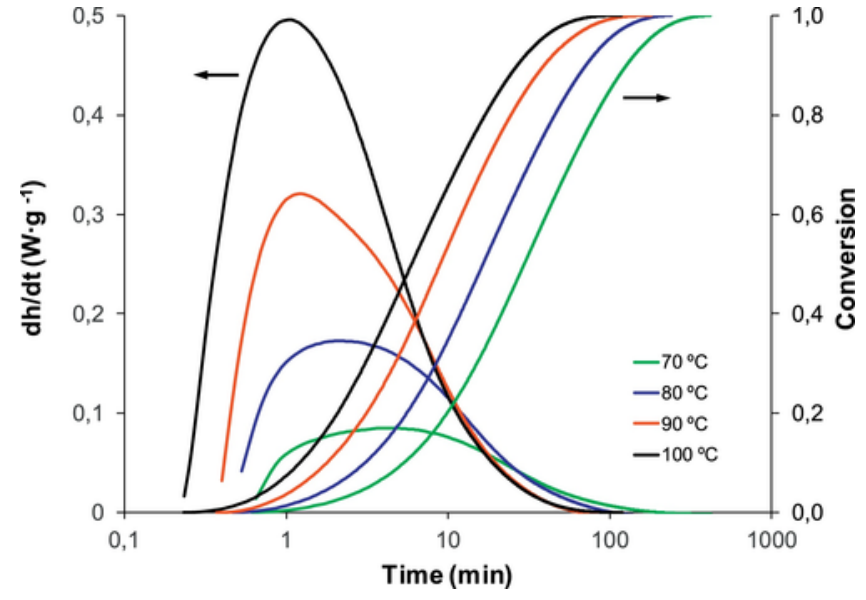

Fig. 5. DSC traces and conversions for the stage 1 process of TGAPJEF50DDS50 isothermally cured at different temperatures.

Table 3

Kinetic parameters determined by isoconversional integral (top) and model fitting analysis (bottom) of stage 1 isothermal curing of TGAPJEF50DDS50.

\begin{tabular}{lllllll}
\hline & $\begin{array}{l}E(k J / \\
m o l)\end{array}$ & $\begin{array}{l}\ln \left[\frac{g(\alpha)}{A}\right] \\
(\mathrm{min})\end{array}$ & $r^{\mathrm{a}}$ & $\begin{array}{l}\ln A^{\mathrm{b}} \\
\left(\mathrm{min}^{-1}\right)\end{array}$ & $\begin{array}{l}k_{180^{\circ} C^{\mathrm{c}}} \\
\left(\mathrm{min}^{-1}\right)\end{array}$ & $\begin{array}{l}\left(\frac{d_{\alpha}}{d t}\right)_{180^{\circ} \mathrm{C}}{ }^{\mathrm{c}} \\
\left(\mathrm{min}^{-1}\right)\end{array}$ \\
\hline 0.1 & 53 & -17.01 & 0.9983 & 15.70 & 4.77 & 2.169 \\
0.2 & 56 & -17.37 & 0.9987 & 16.65 & 4.92 & 2.630 \\
0.3 & 57 & -17.29 & 0.9986 & 16.97 & 6.26 & 2.475 \\
0.4 & 58 & -17.10 & 0.9984 & 17.11 & 6.36 & 2.058 \\
0.5 & 58 & -16.85 & 0.9978 & 17.16 & 6.32 & 1.581 \\
0.6 & 58 & -16.53 & 0.9972 & 17.13 & 6.20 & 1.104 \\
0.7 & 57 & -16.10 & 0.9965 & 17.03 & 6.02 & 0.677 \\
0.8 & 57 & -15.56 & 0.9964 & 16.89 & 5.98 & 0.345 \\
0.9 & 56 & -14.80 & 0.9973 & 16.73 & 6.48 & 0.115 \\
$n$ & $m$ & $E(\mathrm{~kJ} / \mathrm{mol})$ & & $\ln A$ & $r$ & \\
1.74 & 0.26 & 57 & & $\left(\mathrm{~min}^{-1}\right)$ & & \\
\hline
\end{tabular}

a Linear regression coefficient.

b Pre-exponential factor determined by using the isoconversional parameters and the autocatalytic model.

c Rate constant and reaction rate determined at $180^{\circ} \mathrm{C}$ by using Arrhenius equation and Eq. (4).

cients confirm the reliability of the methodology used and of the kinetic parameters. It is observed that activation energies of stage 1 (Table 3) are slightly higher than that of neat TGAPJEF (Table 1). However, the comparison of $k$ or $\mathrm{d} \alpha / \mathrm{d} t$ of Tables 1 and 3 unambigu-

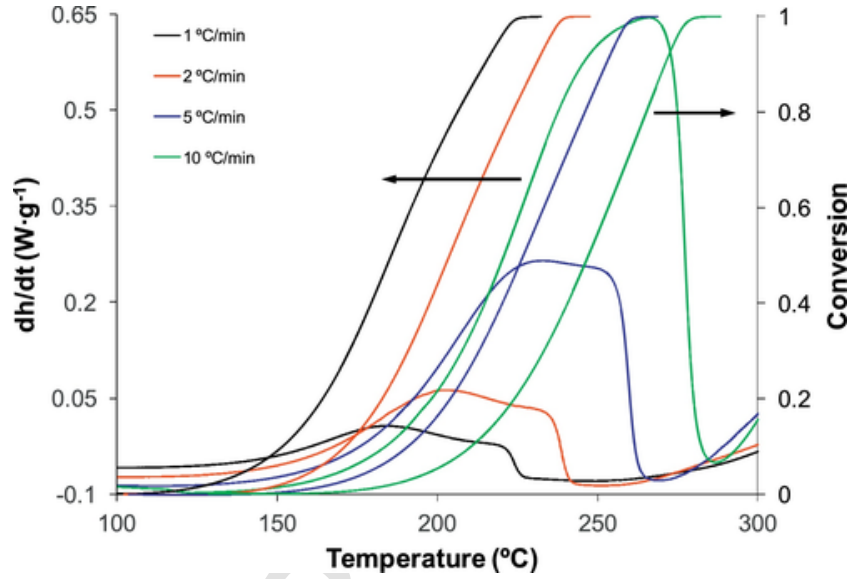

Fig. 6. DSC traces and conversions for the stage 2 (after stage 1 curing at $90^{\circ} \mathrm{C}$ for $180 \mathrm{~min}$ ) of TGAPJEF50DDS50 dynamically cured at different heating rates.

ously show the strong acceleration of stage 1 of the dual formulation in contrast to the neat formulation.

The curing kinetics of stage 2 were analyzed after isothermal curing of fresh formulations at $90^{\circ} \mathrm{C}$ for $180 \mathrm{~min}$. In Fig. 5 it was already demonstrated that this preliminary curing process produced complete conversion of stage 1 and did not affect stage 2 [6]. Although curing stage 2 was also studied isothermally at $150-180^{\circ} \mathrm{C}$ with reasonable results (not shown), it was decided not to use the data for the kinetics analysis due to the uncertainty caused by the incomplete detection of the reaction heat due to loss of heat during the settling time of the equipment and at long curing times where the heat flow may fall below the sensitivity range of the device [16]. Instead, the kinetics of stage 2 were analyzed from dynamic experiments, and the results of the analysis are shown in Fig. 6.

The dynamical kinetic parameters associated to stage 2, determined by using Eqs. (6), (7), (8) and (9) are collected in Table 4. Activation energy values and kinetic model are similar to those obtained for neat TGAPDDS formulation (Table 2) and do not reflect the inhibitive effect of the TGAPJEF network formed during stage 1, shown in Fig. 4. Again, this effect is evidenced by comparing the values of $k$ and $\mathrm{d} \alpha / \mathrm{d} t$ of stage 2 of dual TGAPJEF50DDS50 (Table 4) and neat TGAPDDS (Table 2) formulations. It is clearly observed that the values of neat TGAPDDS are 2-3 times higher than those of TGAPJEF50DDS50 (Stage 2). To summarize, and considering all the curing reactions studied, the kinetic parameters $k$ and $\mathrm{d} \alpha / \mathrm{d} t$ allow establishing the following order of reactivity: TGAPDDS dual (stage 2 ) $<$ neat TGAPDDS $<<$ neat TGAPJEF $<$ TGAP JEF dual (stage 1).

Table 4

Kinetic parameters determined by isoconversional integral and model fitting analysis of dynamic stage 2 curing of TGAPJEF50DDS50.

\begin{tabular}{|c|c|c|c|c|c|c|c|}
\hline$\alpha$ & $E(\mathrm{~kJ} / \mathrm{mol})$ & $\ln \left[\frac{A R}{g(\alpha) E}\right]\left(\min ^{-1}\right)$ & $\ln \left[\frac{g(\alpha)}{A}\right](\min )$ & $r^{a}$ & $\ln A^{b}\left(\min ^{-1}\right)$ & $k_{180^{\circ} C^{c}\left(\min ^{-1}\right)}$ & $\left(\frac{d \alpha}{d t}\right)_{180^{\circ} C}{ }^{c}\left(\min ^{-1}\right)$ \\
\hline 0.1 & 61 & 5.00 & -13.89 & 0.9975 & 13.21 & 0.058 & 0.0166 \\
\hline 0.2 & 63 & 5.06 & -13.99 & 0.9990 & 13.77 & 0.061 & 0.0203 \\
\hline 0.3 & 64 & 5.06 & -14.02 & 0.9995 & 14.10 & 0.060 & 0.0198 \\
\hline 0.4 & 65 & 5.10 & -14.07 & 0.9997 & 14.40 & 0.059 & 0.0176 \\
\hline 0.5 & 67 & 5.19 & -14.18 & 0.9997 & 14.74 & 0.058 & 0.0145 \\
\hline 0.6 & 69 & 5.42 & -14.44 & 0.9998 & 15.23 & 0.057 & 0.0109 \\
\hline 0.7 & 71 & 5.87 & -14.93 & 0.9998 & 15.98 & 0.055 & 0.0074 \\
\hline 0.8 & 76 & 6.66 & -15.78 & 0.9999 & 17.13 & 0.054 & 0.0041 \\
\hline 0.9 & 82 & 7.80 & -17.00 & 0.9998 & 18.81 & 0.056 & 0.0016 \\
\hline$n$ & $m$ & $E(\mathrm{~kJ} / \mathrm{mol})$ & & \multicolumn{2}{|c|}{$\ln A\left(\min ^{-1}\right)$} & \multicolumn{2}{|l|}{$r$} \\
\hline $1-568$ & 0.432 & 67 & & \multicolumn{2}{|l|}{14.99} & \multicolumn{2}{|l|}{0.9934} \\
\hline
\end{tabular}

a Linear regression coefficient.

b Pre-exponential factor determined by using the isoconversional parameters and the autocatalytic model.

c Rate constant and reaction rate determined at $180^{\circ} \mathrm{C}$ by using Arrhenius equation and Eq. (4). 


\subsection{Gelation}

Prior to building the TTT diagram, gelation and $T_{g^{-}} \alpha$ relationship (vitrification), were established. As explained previously, conversions and gelation times were determined by means of isothermal TMA and DSC tests and Table 5 collects the results obtained.

It is generally accepted that gelation occurs at a fixed conversion value which is independent of the curing temperature and depends on the functionality, reactivity, and stoichiometry of the reactive species. Table 5 shows that gelation of TGAPJEF50DDS50 takes place during stage 1 and is an isoconversional phenomenon, with an average absolute $\alpha_{\text {gel }}$ of 0.425 . Solubility tests in dichloromethane gave similar results, so the gel line will be drawn on the TTT diagram as the isoconversional line at 0.425 , obtained in a similar way to the kinetic parameters of the Table 3. The kinetic parameters of the gel line were, $E=57 \mathrm{~kJ} /$ $\mathrm{mol}$ and $\ln [g(\alpha) / A]=-15.23 \mathrm{~min}$. By using Flory-Stockmayer equation [14] a theoretical conversion at gel point of 0.289 , significantly smaller than the experimental one, was obtained. This result, observed in many epoxy-amine formulations, can be explained in terms of intramolecular cycling, that reduces the effective functionality of the system, increasing the experimental $\alpha_{\text {gel }}$ [42]. Flexible amines, such as the JEF used in this work, most likely favour intramolecular loop formation. Gel time increases with decreasing cure temperature and their values agree with the isoconversional line at 0.425 .

Gelation of neat TGAPDDS system was determined using a similar methodology but only at $180^{\circ} \mathrm{C}$. The absolute conversion at gelation $\alpha_{\text {gel }}$ was found to be 0.535 [6].

\section{3. $T_{g^{-}} \alpha$ relationship}

The experimental $T_{g}-\alpha$ relationship of the two stages were established by means of a dynamic postcuring at $10^{\circ} \mathrm{C} / \mathrm{min}$ of samples partially cured for different durations at $90^{\circ} \mathrm{C}$ (stage 1 ) and $180^{\circ} \mathrm{C}$ (stage 2). Fig. 7 shows the residual DSC traces of samples partially cured at $90^{\circ} \mathrm{C}$ (stage 1). As can be seen, $T_{g}$ increases and the residual heat decreases on increasing the curing time. The first peak disappears completely at $180 \mathrm{~min}$ and the second peak, associated at TGAPDDS condensation, remains constant, indicating than DDS did not react during stage 1. During stage 2 at $180^{\circ} \mathrm{C}$, the decreasing of the second exotherm and the increasing of $T_{g}$ was observed (not shown). The peak associated to stage 1 is not observed during stage 2 (see Fig. 4) since it had disappeared completely after stage 1 .

There are various theoretical models of the effect of the degree of crosslinking on the $T_{g}$. A widely accepted model was proposed by Nilsen and DiBenedetto, which was later adapted by Pascault and Williams [43-45]:

Table 5

Experimental gelation data obtained by isothermal DSC/TMA combined assays of TGAPJEF50DDS50 formulation.

\begin{tabular}{llll}
\hline$T\left({ }^{\circ} \mathrm{C}\right)$ & $\alpha_{\text {gel }} \mathrm{a}^{\mathrm{a}}$ & $\alpha_{\text {gel }}{ }^{\mathrm{b}}$ & $t_{\text {gel }}(\mathrm{min})$ \\
\hline 70 & 0.85 & 0.425 & 100 \\
80 & 0.84 & 0.420 & 54 \\
90 & 0.85 & 0.425 & 33 \\
100 & 0.86 & 0.430 & 22 \\
\hline
\end{tabular}

a Relative conversion (stage 1).

b Absolute conversion (total curing).

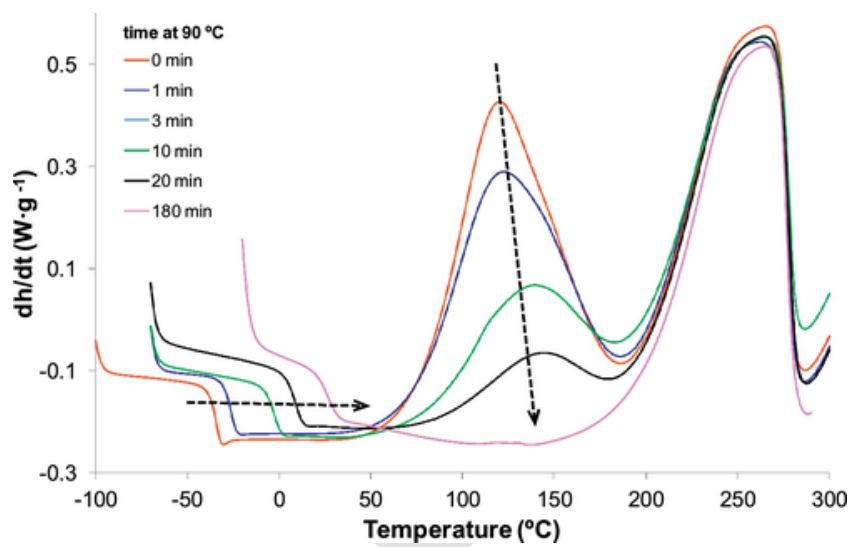

Fig. 7. Experimental determination of the $T_{g}-\alpha$ relationship for the first curing stage of stage 1 of TGAPJEF50DDS50 formulation.

$\frac{T_{g}-T_{g 0}}{T_{g \infty}-T_{g 0}}=\frac{\lambda \alpha}{1-(1-\lambda) \alpha}=\frac{\frac{\Delta C_{p_{\infty}}}{\Delta C_{p 0}}}{1-\left(1-\frac{\Delta C_{p \infty}}{\Delta C_{p 0}}\right) \alpha}$

where $T_{g o}, T_{g \infty}, \Delta C_{p o}$, and $\Delta C_{p \infty}$ are the glass transition temperatures and the increases in heat capacity during glass transition of uncrosslinked (o) and crosslinked $(\infty)$ thermosets and $\lambda$ is the quotient of segment mobilities, that can be considered an adjustable parameter between 0 and 1 or the quotient between $\Delta C_{p \infty}$ and $\Delta C_{p o}$ [45]. In this work it was taken $\lambda=\Delta C_{p \infty} / \Delta C_{p o}$ [13] and the theoretical $T_{g^{-}} \alpha$ relationship was represented by using Eq. (11) and the experimental parameters collected in Table 6 for each stage. Taking into account that the intermediate material refers to the material just after stage 1 (or equivalently, the material just before stage 2), $T_{g 1}-\alpha$ (stage 1) was determined using of $T_{g o}, T_{\text {gint }}$, $\Delta C_{p o}$, and $\Delta C_{\text {pint }}$ and $T_{g 2^{-}} \alpha$ (stage 2) using $T_{\text {gint }}, T_{\text {gint }}, T_{g \infty}$ and $\Delta C_{p \infty}$. Conversion $\alpha$ is taken as the absolute conversion and varies between 0 and 0.5 and between 0.5 and 1 during stage 1 and stage 2, respectively.

The higher value of $\lambda_{1}$ indicates that there is less croslinking in stage 1 than in stage 2 , which is consistent with the fact that gelation takes place at the end of stage 1 at the absolute conversion of 0.425 (relative conversion of 0.85 ) and with fact of TGAPDDS network has higher concentration of crosslinking points than TGAPJEF network [6].

Fig. 8 shows the curves $T_{g}$ against absolute conversion obtained experimentally and theoretically for both curing process and how experimental data fit well with theoretical data. As a consequence, Eq. (11) that only requires values of $T_{g}$ and $\Delta C_{p}$, before and after curing, to be applied, it will be used to predict the vitrification conversion at each curing temperature.

The $T_{g^{-}} \alpha$ relationship of neat TGAPDDS formulation was also determined using the simplified method given by Eq. (11) and the following

Table 6

Parameters for the determination of the $T_{g}-\alpha$ relationship of TGAPJEF50DDS50 formulation using theoretical expression Eq. (11).

\begin{tabular}{lll}
\hline & $T_{g}\left({ }^{\circ} \mathrm{C}\right)$ & $\Delta C_{p}(\mathrm{~kJ} / \mathrm{kg} \cdot \mathrm{K})$ \\
\hline \multirow{2}{*}{ Unreacted material (0) } & -35 & 0.67 \\
Intermediate material (int) & 27 & 0.45 \\
Final material ( $\infty$ ) & 120 & 0.22 \\
\hline \multicolumn{2}{c}{ Stage 1 } & \multicolumn{2}{c}{ Stage 2 } \\
\hline \multirow{2}{*}{0.67} & \multicolumn{2}{c}{0.49} \\
\hline
\end{tabular}




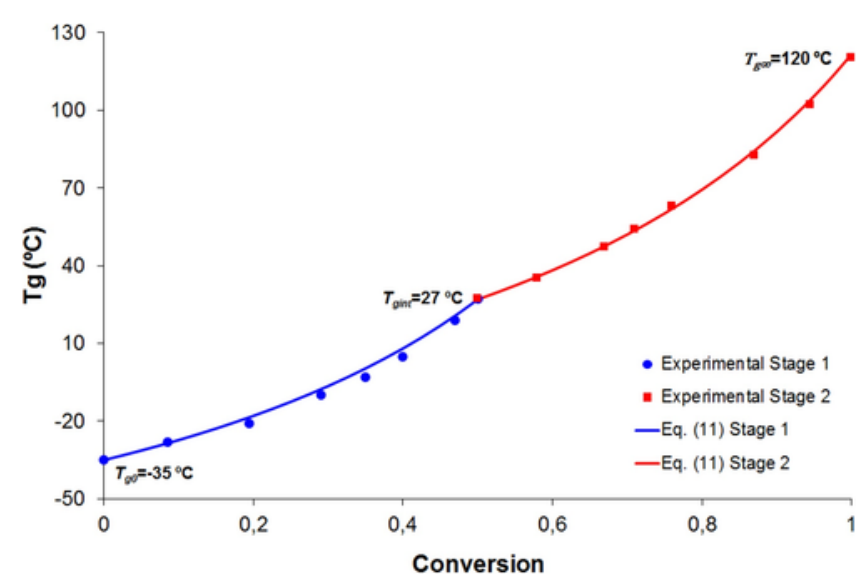

Fig. 8. $T_{g}-\alpha$ relationship for the curing process of TGAPJEF50DDS50 formulation determined experimentally and theoretically by using Eq. (11).

experimental data reported in a previous work [6]: $T_{g 0}=-16^{\circ} \mathrm{C}$, $\Delta C_{p 0}=0.430 \mathrm{~J} / \mathrm{g} \cdot \mathrm{K}, T_{g \infty}=235^{\circ} \mathrm{C}$ and $\Delta C_{p \infty}=0.1 \mathrm{~J} / \mathrm{g} \cdot \mathrm{K}$

\subsection{Time-temperature-transformation (TTT) diagram}

The TTT diagram for the TGAPJEF50DDS50 formulation was built using the experimental data determined previously, following the general methodology described in Section 3.2. In more specific terms:

(1) The isoconversional lines were traced in the TTT diagram using Eq. (5) and isothermal kinetic parameters (Table 3) for stage 1 and non-isothermal kinetic parameters for stage 2 (Table 4) obtained at different conversions. Note that plotting of the isoconversional lines until the vitrification line implies a significant extrapolation beyond the experimental range of the kinetic analysis, so inaccurate kinetic data can lead to the crossing of the isoconversional lines near vitrification. For this reason, as it was explained previously, isothermal kinetic data was not used in stage 2 . Tables 3 and 4 show relative conversion at each stage, but for the sake of clarity, absolute conversion was used in the TTT diagram. Absolute conversions were calculated as $0.5 \cdot \alpha$ at stage 1 and $0.5+0.5 \cdot \alpha$ at stage 2 , assuming that stage 1 is completed before stage 2 starts.

(2) $T_{g 0} T_{\text {gint, }} T_{g_{\infty}}, \Delta C_{p 0}, \Delta C_{\text {pint }}$ and $\Delta C_{p \infty}$ were determined by heating initial, intermediate and fully cured samples at $10^{\circ} \mathrm{C} / \mathrm{min}$ in DSC

(3) Gelation line were drawn using Eq. (5) applied to the absolute average conversion of $0.425\left(\alpha_{\text {gel }}\right)$ determined using TMA and DSC (Table 5). The extrapolation is performed by first inserting $E=57 \mathrm{~kJ} / \mathrm{mol}$ and $\ln [g(\alpha) / A]=-15.23 \mathrm{~min}$, which were determined by the isoconversional method for $\alpha=0.425$, in Eq. (5). Using this equation, the isoconversional line is drawn for the temperature ranging from $200^{\circ} \mathrm{C}$ to $14.1^{\circ} \mathrm{C}$, the latter of which is the $T_{g}$ that corresponds to a conversion of 0.425 . This $T_{g}$ is to be calculated from The DiBenedetto $T_{g}-\alpha$ relation (i.e. Eq. (11), stage 1 ).

(4) Assuming that the isoconversional lines are valid until vitrification is reached (at which time the reaction shifts from a chemically controlled to a diffusion control regime), vitrification time was taken as the time to reach the conversion (isoconversional line) at which $T_{g}$ is equal to the curing temperature, $T_{c}$. The values of $T_{g}$ at each conversion were estimated from data given in Table 6 and $T_{g}$ - $\alpha$ relationship given by Eq. (11), that agrees the experimental values (see Fig. 8). The vitrification lines were finally determined joining the end points of the isoconversional lines at $T_{g}=T_{c}$.

(5) Since gelation is an isoconversional phenomenon, ${ }_{g e l} T_{g}$, was determined as the temperature at which the material vitrifies with a conversion equal to $\alpha_{\text {gel }}=0.425$. The time needed for the material to gel and vitrify simultaneously was determined by extrapolating the isoconversional line of $\alpha_{g e l}$ up a curing temperature equal to ${ }_{g e l} T_{g}$.

Fig. 9 plots de TTT diagram corresponding to the curing of TGAPJEF50DDS50 formulation constructed using the methodology explained. In order to validate the methodology, TTT diagram also features some experimental data.

TTT diagram shows clearly that there are two sets of isoconversional lines corresponding to the first and second curing stages, which are independent from each other throughout the complete range of temperatures shown. The wide separation between the right-most isoconversional line of stage 1 and the left-most line of stage 2 indicates that there should be no overlapping between stages at any heating rate, as suggested also by Fig. 4. This is of highly practical importance for multi-stage applications, i.e. B-staging. In this dual curing systems the curing process slows down and virtually stops when the first curing reaction is over, therefore making it easy to control the degree of cure and therefore the structure and properties of the intermediate material, which can be stored or manipulated safely before the final application. The suitability of the kinetic methodology used is validated by the agreement between experimental data and the isoconversional lines drawn, including the gelation line. Only isothermal curing data from stage 2 shows a slightly worse adjustment. As was already mentioned, non-isothermal curing data were used instead for the determination of the isoconversional lines of stage 2 .

The existence of two curing stages with different kinetics and structure build-up ( $T_{g}-\alpha$ relationship) is also evidenced by the shape of the vitrification line, which is composed of two S-shape curves joining at $T_{\text {gint }}$ This feature was observed in a previous work [12] for a dual system consisting of a self-limiting epoxy-amine polycondensation at a moderately elevated temperature followed by anionic epoxy homopolymerization initiated by a latent base. Observing the TTT diagram and in accordance with $T_{\text {gint }}$ and $T_{g \infty}$ values, it can be stated that vitrification does not take place in any of the curing stages, within the experimental range of curing temperatures, and hence vitrification can be disregarded in the kinetic analysis, from a practical point of view. At temperatures lower than experimental ones, vitrification can take place only after impractically long times. Nevertheless, to validate the methodology used, a sample was cured below room temperature at $15^{\circ} \mathrm{C}$ and an experimental vitrification time of 4168 min was measured by DSC. TTT diagram shows that this point agrees perfectly with the vitrification line, simultaneously confirming the goodness of extrapolation of the isoconversional lines and of the determination of experimental vitrification.

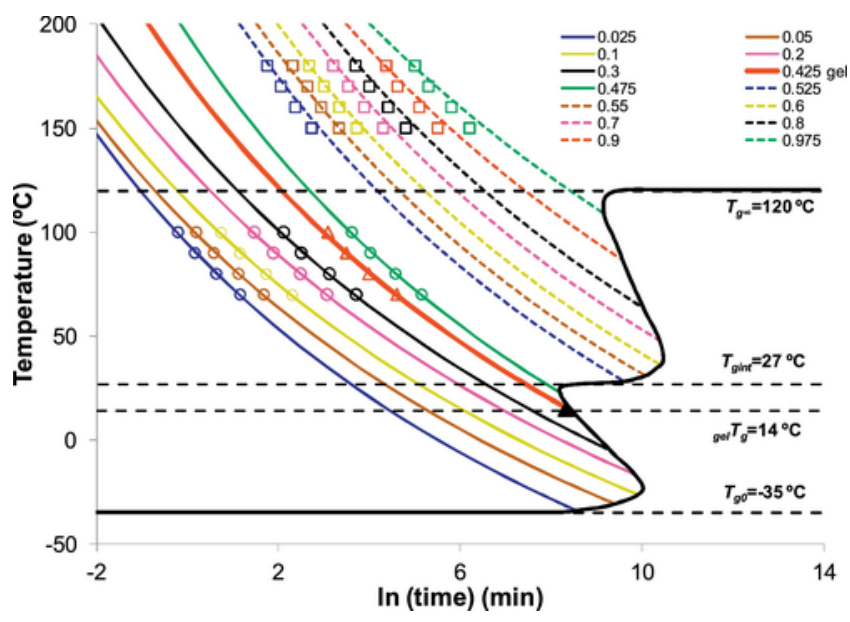

Fig. 9. TTT cure diagram of the TGAPJEF50DDS50 formulation. Isothermal experimental data (stage 1 , empty circle) (stage 2 , empty squares) (gelation, empty triangle) and (vitrification by TMDSC, solid black triangle) are also shown. 
The storage stability of the intermediate material is another remarkable feature of this system. This material can be stored almost indefinitely at temperatures below $T_{\text {gint }}=27^{\circ} \mathrm{C}$ (ca. $20-25^{\circ} \mathrm{C}$ ) since in the glassy state, the second curing process is unable to start. At $30^{\circ} \mathrm{C}$, the difference between isoconversional lines $\alpha=0.475$ (final part stage 1) and $\alpha=0.525$ (initial part of stage 2) is in the range of 7 days, once more indicating a high storage stability at any near-ambient temperature. In intermediate formulations stored above $T_{\text {gint }}$ (e.g. $30-35^{\circ} \mathrm{C}$ ), curing would slightly progress, but when the $T_{g}$ reaches storage temperature, the material would vitrify and thus permit storage for an indefinite period of time. These results strongly agree with those reported in a previous work [6], where intermediate TGAPJEF50DDS50 formulation stored at $30^{\circ} \mathrm{C}$ experienced a small increase in $T_{g}$ in the first 10 days and then it was stable for the next two months because it had already vitrified. In addition, the TTT diagram also indicates that the fresh formulation can be safely stored at room temperature at least two days without risk of gelation. Samples stored in a fridge $\left(\right.$ ca. $5{ }^{\circ} \mathrm{C}$ ) or freezer (ca. $-18^{\circ} \mathrm{C}$ ) can be stored for long periods of time since they would vitrify before gelation takes place $\left(g e l T_{g}=14^{\circ} \mathrm{C}\right)$.

In order to highlight the main features and benefits of dual curing formulations, it was decided to build the TTT diagram of a conventional formulation, TGAPDDS, using the same methodology as in Section 3.2, shown in Fig. 10. The isoconversional kinetic parameters of Table 2 and the following experimental data reported in a previous work [6]: $T_{g 0}=-16^{\circ} \mathrm{C}, \Delta C_{p 0}=0.430 \mathrm{~J} / \mathrm{g} \cdot \mathrm{K}, T_{g \infty}=235^{\circ} \mathrm{C}$ and $\Delta C_{p \infty}=0.1 \mathrm{~J} / \mathrm{g} \cdot \mathrm{K}$. Since TGAPDDS formulation that has a $T_{g}$ of $235^{\circ} \mathrm{C}$ it can vitrify in a wide range of practical curing temperatures. Experimental vitrification times at several curing temperatures determined by TMDSC were also included. As can be seen, the vitrification times obtained by extrapolation of the isoconversional lines at $T_{g}=T_{c}$ (i.e. curing temperature) agree well to those obtained isothermally by TMDSC.

When Fig. 9 is compared to Fig. 10, remarkable differences between dual curing and conventional curing systems are revealed, in terms of processability and flexibility. As has been mentioned before, the existence of two different reactions with different kinetics and intermediate stability in the dual curing system (Fig. 9) makes them especially suitable for multi-stage applications such as B-staging. In contrast, in the conventional system TGAPDDS (Fig. 10) there is a single set of isoconversional lines that are very close to each other and the vitrification line has the common S-shape. TGAPDDS would require a careful control of time-temperature during first stage processing in order to avoid an excessive degree of cure, which could render the component unusable. In addition, control of the extent of cure by vitrification might be unsuitable depending on the desired intermediate conversion. In contrast, such limitation could be easily overcome in the dual curing sys-

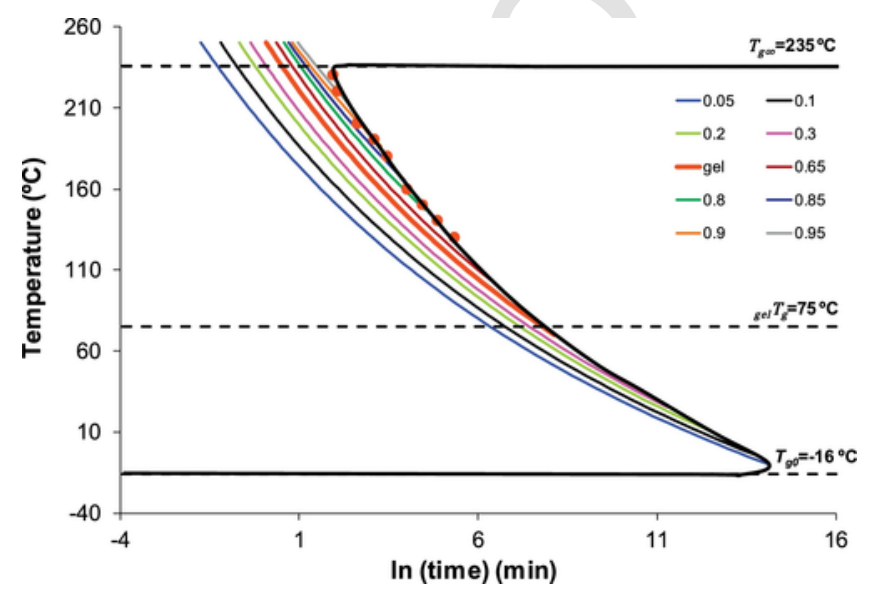

Fig. 10. TTT cure diagram of the TGAPJEFDDS formulation. Experimental vitrification times obtained by TMDSC (circles) are also shown. tem TGAPJEF50DDS50. This kinetic control and the possibility of adjusting the extent of cure and therefore the intermediate properties just by changing the structure and feed ratio of the monomers make dual curing systems highly flexible and particularly suitable for multi-stage applications. Other applications such as the processing of composites by resin transfer molding (RTM) can also benefit from the use of dual curing systems because their intrinsic staged curing behaviour makes it easier to control temperature and conversion profiles during processing [46].

Some comments can be made with regards to the methodology employed to determine the TTT diagram. The methodology to analyze the curing kinetics, predict isoconversional lines and determine gel point conversion is well established and reliable and deserves no specific discussion. However, a significant extrapolation is made outside the experimental temperature range, and this is always a source of error. In addition, there is significant uncertainty in the determination of the vitrification line. Vitrification is a transition rather than a point-like event and it can also have a significant effect on curing kinetics, both of which are disregarded in the present methodology, based on the extrapolation of the isoconversional line up to $T_{g}=T_{c}$.

The vitrification time, $t_{v}$, can be determined as the point where the $T_{g}=T_{c}$ [29] by conventional DSC using the so-called method of partial curing, where the samples are cured separately for different durations, and then submitted to a DSC analysis in order to determine the $T_{g}$ and the conversion. This method is accurate but requires a lot of experiments for each $t_{v}$. Other methodologies entail curing the sample by techniques sensitive to vitrification, such as Torsional Braid Analysis [47], Dynamic Mechanical Analysis [48] or Rheometry [49]. In this case, the $t_{v}$ is determined directly as the time needed to reach a maximum value of signal at a given curing temperature. A drawback of such techniques is the determination of the vitrification conversion for which the experiment should be stopped, the sample inserted in a hermetically sealed DSC pan and a postcuring performed. During this prep time, the curing continues and the conversion increases. Vitrification conversion can be determined directly by $t_{v}$ and conversion-time curve obtained by isothermal DSC, but inaccuracies can arise due to the different temperature control of the different equipments. Hyphenated techniques such as RheoDSC device aims [8] to solve this problem, but the design of the equipment is complex [50].

In this work we chose to use TMDSC for the experimental determination of vitrification (see Fig. 1), using a modulation period sufficiently high so as to make $t_{v}$ quasi-independent from the modulation period [51]. Because the reaction heat flow is being measured during the experiment, uncertainty in the determination of $t_{v}$ is highly reduced. The values of the $t_{v}$ obtained by the traditional method of partial curing agree well with those obtained by the variation in complex heat capacity obtained by TMDSC [29]. Alternatively, a relatively new modulated DSC technique, TOPEM, allows to determine the so-called quasi-static heat capacity, which yields a vitrification time independent of the period $[32,51]$. However, a significant problem inherent to the determination of vitrification is the definition of $t_{v}$. By means of TMDSC three different $t_{v}$ can be defined, the extrapolated onset $t_{v, 0}$, the extrapolated midpoint $t_{v, m p}$ and the extrapolated endset $t_{v, \text { end }}$ (see Fig. 1 ). The choice of which $t_{v}$ to include in the analysis is arbitrary since each shows a different moment of vitrification. However, it was found in this work that there was an excellent agreement between the experimental $t_{v, \text { end }}$ determined with TMDSC and the determination of the vitrification line by extrapolation of isoconversional curves up to $T_{g}=T_{c}$ at each conversion. This method has been found to be simple and reproducible as it offers good results for both TGAPJEF50DDS50 (Fig. 9) and TGAPDDS (Fig. 10). If $t_{v, m p}$ had been used, the experimental vitrification curve would have the same shape but slightly displaced towards shorter times. 
In summary, the TTT diagram is a powerful tool to select and optimize processing temperatures and to eliminate the risk of pre-curing or under-curing of components. This is made evident in dual formulations, TTT-diagram allows establishing optimal curing conditions to achieve sequentiality and storage stability of intermediate materials. It is also demonstrated that simple methodologies, based on a reduced set of experimental measurements, can be confidently used to build TTT diagrams with practical application.

\section{Conclusions}

The curing kinetics, the gelation and the vitrification of a dual-curable epoxy thermoset based on two sequential epoxy-amine condensations has been studied, and the results have been used to build a time-temperature-transformation (TTT) cure diagram. This has been compared with the TTT diagram of a conventional curing system and the differences have been discussed.

The different reactivity of each curing stage due to the different nucleophilicities of the amines was confirmed in the kinetics analysis. The interaction between the curing stages leads to an acceleration of the first curing stage (TGAP-JEF condensation) and a deceleration of the second curing stage (TGAP-DDS). This interaction helps achieve a higher separation between the range of temperatures of each curing stage, consequently allowing better sequentiality of the dual curing. In general, the isoconversional activation energies agree with the observed kinetics, whereas in some systems with similar activation energies, the kinetics are better represented by the rate constant or the reaction rates, both estimated by the kinetic model assumed.

The methodology used for the construction of TTT diagram involves only a few experiments. Despite the fact that some data are obtained by extrapolation of the kinetic adjustments, the gelation and vitrification lines agree well with experimental results. The robustness of the isoconversional kinetic parameters, obtained without the necessity of mechanistic hypotheses, also contributed to the success of the analysis. The methodology is generally applicable and can be used for the curing of other thermoset systems.

The TTT diagram summarizes, in a graphical and concise way, the main features of curing, with particular appeal for dual-curing systems. The long storage stability of the intermediate material at room temperature, confirmed with experiments, is well represented. This stability is controlled by the low reactivity of the aromatic amine and by the vitrifitication of intermediate material which prevents the initiation of the second curing stage. TTT diagram is a guide to select optimal temperatures and times of curing to control the curing sequence well. It allows selection of safe storage times and temperatures for uncured and intermediate samples. A good temporal separation between the two curing stages leads to quasi-independent reaction processes, thus a careful selection of temperatures would allow perfect sequentiality of the dual-curing. Finally, the TTT diagram exhibits two S-shaped vitrification curves that reflect the different network build-up characteristics and kinetics of each curing stage.

Differences between the TTT diagram of dual and conventional curing systems serve to highlight the enhanced features of dual curing systems in terms of processing ability and flexibility. Multi-stage applications or composite processing can strongly benefit from the use of dual curing systems.

\section{Acknowledgments}

The authors would like to thank MCIU (Ministerio de Ciencia, Innovación y Universidades) and FEDER (Fondo Europeo de Desarrollo Regional) ( MAT2017-82849-C2-2-R) and Generalitat de Catalunya (2017-SGR-77 and Serra Húnter program) for the financial support.

\section{References}

[1] X. Ramis, X. Fernández-Francos, S. De La Flor, F. Ferrando, À. Serra, Click-based dual-curing thermosets and their applications, in: Q. Guo (Ed.), Structure, Properties and Application, 2nd ed., Elsevier, 2018, pp. 511-541, https://doi.org/10. 1016/B978-0-08-101021-1.00016-2, Thermosets Ch.16.

[2] D.P. Nair, N.B. Cramer, J.C. Gaipa, M.K. McBride, E.M. Matherly, R.R. McLeod, R Shandas, C.N. Bowman, Two-stage reactive polymer network forming systems, Adv. Funct. Mater. 22 (2012) 1502-1510, https://doi.org/10.1002/adfm. 201102742.

[3] O. Konuray, N. Areny, J.M. Morancho, X. Fernández-Francos, A. Serra, X. Ramis, Preparation and characterization of dual-curable off-stoichiometric amine-epoxy thermosets with latent reactivity, Polymer 146 (2018) 42-52, https://doi.org/10. 1016/j.polymer.2018.05.040.

[4] O. Konuray, X. Ramis, X. Fernández-Francos, À. Serra, State of the art in dual-cur ing acrylate systems, Polymers 10 (178) (2018) 1-24, https://doi.org/10.3390/ polym10020178.

[5] W. Xi, H. Peng, A. Aguirre-Soto, C.J. Kloxin, J.W. Stansbury, C.N. Bowman, Spatial and temporal control of thiol-Michael addition via photocaged superbase in photopatterning and two-stage polymer networks formation, Macromolecules 47 (2014) 6159-6165, https://doi.org/10.1021/ma501366f.

[6] O. Konuray, A. García, J.M. Morancho, X. Fernández-Francos, À. Serra, F. Ferrando, M. García-Alvarez, X. Ramis, Hard epoxy thermosets obtained via two sequential epoxy-amine condensations, Eur. Polym. J. 116 (2019) 222-231, https:// doi.org/10.1016/j.eurpolymj.2019.04.018.

[7] M.T. Aronhime, J.K. Gillham, Time-Temperature-Transformation (TTT) Cure Diagram of Thermosetting Polymeric Systems, Springer-Verlag, Berlin, West Ger, 198683.113

[8] C. Block, B. Van Mele, P. Van Puyvelde, G. Van Assch, Time-temperature-transformation (TTT) and temperature-conversion-transformation (TxT) cure diagrams by RheoDSC: combined rheometry and calorimetry on an epoxy-amine thermoset, React. Funct. Polym. 73 (2013) 332-339, https://doi.org/10.1016/j.reactfunctpolym. 2012.05.009.

[9] D. Santiago, X. Fernàndez-Francos, X. Ramis, J.M. Salla, M. Sangermano, Comparative curing kinetics and thermal-mechanical properties of DGEBA thermosets cured with a hyperbranched poly(ethyleneimine) and an aliphatic triamine, Thermochim. Acta 526 (2011) 9-21, https://doi.org/10.1016/j.tca.2011.08.016.

[10] H. Teil, S.A. Page, V. Michaud, J.A.E. Manson, TTT-cure diagram of an anhydride cured epoxy system including gelation, vitrification, curing kinetics model, and monitoring of the glass transition temperature, J. Appl. Polym. Sci. 93 (2004) 1774-1787, https://doi.org/10.1002/app.20631.

[11] N.C. Restrepo-Zapata, T.A. Osswald, J.P. Hernández-Ortiz, Method for time-temperature-transformation diagrams using DSC data: linseed aliphatic epoxy resin, J. Appl. Polym. Sci. 40566 (2014) 1-13, https://doi.org/10.1002/APP.40566.

[12] N. Areny, O. Konuray, X. Fernàndez-Francos, J.M. Salla, J.M. Morancho, X. Ramis, Time-temperature-transformation (TTT) diagram of a dual-curable off stoichiometric epoxy-amine system with latent reactivity, Thermochim. Acta 666 (2018) 124-134, https://doi.org/10.1016/j.tca.2018.06.012.

[13] X. Ramis, J.M. Salla, Time-temperature transformation (TTT) cure diagram of an unsaturated polyester resin, J. Polym. Sci.: Part B: Polym. Phys 35 (1997) 371-388, https://doi-org.recursos.biblioteca.upc.edu/10.1002/( SICI)1099-0488(19970130)35:2<371::AID-POLB13> 3.0.CO;2-F

[14] J.P. Pascault, H. Sautereau, J. Verdu, R.J.J. Williams, Thermosetting Polymers, Marcel Dekker, New York, 2002

[15] J.P. Pascault, R.J.J. Williams, Overview of thermosets: present and future, in: Q. Guo (Ed.), Structure, Properties and Application, 2nd ed., Elsevier, 2018, pp. 3-34, https://doi.org/10.1016/B978-0-08-101021-1.00001-0, Thermosets Ch.11.

[16] S. Vyazovkin, A.K. Burnham, J.M. Criado, L.A. Pérez-Maqueda, C. Popescu, N. Sbirrazzuoli, ICTAC kinetics committee recommendations for performing kinetic computations on thermal analysis data, Thermochim. Acta 520 (2011) 1-19, https: //doi.org/10.1016/j.tca.2011.03.034.

[17] A. Cadenato, J.M. Morancho, X. Fernández-Francos, J.M. Salla, X. Ramis, Comparative kinetic study of the non-isothermal thermal curing of bis-GMA/TEGDMA systems, J. Thermal Anal. Cal. 89 (2007) 233-244, https://doi.org/10.1007/s10973006-7567-5.

[18] A. Belmonte, F. Dabritz, X. Ramis, A. Serra, B. Voit, X. Fernandez-Francos, Cure kinetics modeling and thermomechanical properties of cycloaliphatic epoxy-anhydride thermosets modified with hyperstar polymers, J. Polym. Sci. Part B: Polym. Phys. 52 (2014) 1227-1242, https://doi.org/10.1002/polb.23555.

[19] D. Santín, O. Konuray, X. Fernàndez-Francos, X. Ramis, Kinetics analysis and simulation of sequential dual-curing systems with independent thermal activation, Thermochim. Acta 673 (2019) 158-168, https://doi.org/10.1016/j.tca.2019.01. 023.

[20] M. Flores, X. Fernández-Francos, X. Ramis, A. Serra, Novel epoxy-anhydride thermosets modified with a hyperbranched polyester as toughness enhancer. I. Kinetics study, Thermochim. Acta 544 (2012) 17-26, https://doi.org/10.1016/j.tca.2012. 06.00 .

[21] T. Akahira, T. Sunose, Method of determining activation deterioration constant of electrical insulating materials, Res. Report Chiba Inst. Technol. (Sci. Technol.) 16 (1971) 22-31.

[22] A.W. Coats, J.P. Redfern, Kinetic parameters from thermogravimetric data, Nature 207 (1964) 68-69, https://doi.org/10.1038/201068a0. 
[23] L.A. Perez-Maqueda, J.M. Criado, P.E. Sanchez-Jimenez, Combined kinetic analysis of solid-state reactions: a powerful tool for the simultaneous determination of kinetic parameters and the kinetic model without previous assumptions on the reaction mechanism, J. Phys. Chem. A 110 (2006) 12456-12462, https://doi.org/10. 1021/jp064792g.

[24] P.I. Karkanas, I.K. Partridge, Cure modeling and monitoring of epoxy/amine resin systems. I. Cure kinetics modeling, J. Appl. Polym. Sci. 77 (2000) 1419-1431, https://doi-org.recursos.biblioteca.upc.edu/10.1002/ 1097-4628(20000815)77:7 < 1419::AID-APP3 > 3.0.CO;2-N

[25] J.M. Morancho, X. Ramis, X. Fernández-Francos, J.M. Salla, A.O. Konuray, A. Serra, Curing of off-stoichiometric amine-epoxy thermosets, J. Thermal Anal. Cal. 133 (2018) 1519-1527, https://doi.org/10.1007/s10973-018-71582(0123456789.

[26] K.C. Cole, A new approach to modelling the cure kinetics of epoxy amine thermosseting resins. 1. Mathematical development, Macromolecules 24 (1991) 3093-3097, https://doi.org/10.1021/ma00011a011.

[27] K.C. Cole, J.-J. Hechler, D. Noël, A new approach to modelling the cure kinetics of epoxy amine thermosseting resins. 2. Application to a typical system based on bis[4-(diglycidylamino)phenyl]methane and bis(4-aminophenyl) sulfone, Macromolecules 24 (1991) 3098-3110, https://doi.org/10.1021/ma00011a012.

[28] D. Verchère, H. Sautereau, J.P. Pascault, C.C. Riccardi, S.M. Moschiar, R.J.J. Williams, Buildup of epoxycycloaliphatic amine networks. Kinetics, vitrification and gelation, Macromecules 23 (1990) 725-731, https://doi.org/10.1021/ ma00205a006.

[29] S. Montserrat, I. Cima, Isothermal curing of an epoxy resin by alternating differential scanning calorimetry, Thermochim. Acta 330 (1990) 189-200, https://doi.org/ 10.1016/S0040-6031(99)00033-7.

[30] S. Vyazovkin, N. Sbirrazzuoli, Mechanism and kinetics of epoxy-amine cure studied by differential scanning calorimetry, Macromolecules 29 (1996) 1867-1873, https: //doi.org/10.1021/ma951162w.

[31] F. Shiravand, J.M. Hutchinson, Y. Calventus, Influence of the isothermal cure temperature on the nanostructure and thermal properties of an epoxy layered silicate nanocomposite, Polym. Eng. Sci. 54 (2014) 51-58, https://doi.org/10.1002/pen. 23540.

[32] J.M. Hutchinson, F. Shiravand, Y. Calventus, I. Fraga, Isothermal and non-isothermal cure of a tri-functional epoxy resin (TGAP): a stochastic TMDSC study, Thermochim. Acta 529 (2012) 14-21, https://doi.org/10.1016/j.tca.2011.11.008.

[33] R.J. Varley, J.H. Hodgkin, D.G. Hawthorne, G.P. Simon, Toughening of a trifunc tional epoxy system. II. Thermal characterization of epoxy/amine cure, J. Appl. Polym. Sci. 60 (1996) 2251-2263, https://doi.org/10.1002/(SICI)10974628(19960620)60:12<2251::AID-APP24 > 3.0.CO;2-8.

[34] C. Zhang, Y. Wang, Y. Liu, Construction of improved isothermal TTT cure diagram based on an epoxy-amine thermoset, J. Appl. Polym. Sci. 47279 (2019) 1-8, https: //doi.org/10.1002/APP.47279.

[35] S. Swier, G. Van Assche, B. Van Mele, Reaction kinetics modeling and thermal properties of epoxy-amines as measured by modulated-temperature DSC. I. Linear step-growth polymerization of DGEBA + aniline, J. Appl. Polym. Sci. 9 (2019) 2798-2813, https://doi.org/10.1002/app.13466.

[36] J. Mijovic, J. Wijaya, Reaction kinetics of epoxy/amine model systems. The effect of electrophilicity of amine molecule, Macromolecules 27 (1994) 7589-7600, https://doi.org/10.1021/ma00104a013.
[37] I. Fraga, J.M. Hutcchinson, S. Montserrat, Vitrification and devitrification during the non-isothermal cure of a thermoset, Thermal Anal. Cal. 99 (2010) 925-929, https://doi.org/10.1007/s109.

[38] E. Girard-Reydet, C.C. Riccardi, H. Sautereau, J.P. Pascault, Epoxy-aromatic diamine kinetics. Part 1. Modeling and influence of the diamine structure, Macromolecules 28 (1995) 7599-7607, https://doi.org/10.1021/ma00127a003.

[39] V. Antonucci, M. Giordano, L. Nicolais, Effect of the segmental mobility restriction on the thermoset chemical kinetics, J. Polym. Sci., Part A: Polym. Chem. 40 (2002) 3757-3770, https://doi.org/10.1002/pola.10471.

[40] S. Vyazovkin, C.A. Wight, Kinetic in solids, Annu. Rev. Phys. Chem. 48 (1997) 125-149, https://doi.org/10.1146/annurev.physchem.48.1.125.

[41] S. Swier, G. Van Assche, W. Vuchelen, B. Van Mele, Role of complex formation in the polymerization kinetics of modified epoxy-amine systems, Macromolecules 38 (2005) 2281-2288, https://doi.org/10.1021/ma047796x.

[42] Y. Tanaka, J.L. Stanford, R. Stepto, Interpretation of gel points of an epoxyamine system including ring formation and unequal reactivity: measurements of gel points and analyses on ring structures, Macromolecules 45 (2012) 7197-7205, https://doi.org/10.1021/ma300984u.

[43] L.E. Nielsen, Crosslinking-effect on physical properties of polymers, J. Macromol. Sci. Macromol. Chem. C3 (1) (1969) 69-103.

[44] A.T. Dibenedetto, Prediction of the glass transition temperature of polymers: a model based on the principle of corresponding states, J. Polym. Sci. Part B: Polym. Phys. 25 (1987) 1949-1969 https://doi-org.recursos.biblioteca.upc.edu/10.1002/ polb.1987.090250914.

[45] J.P. Pascault, R.J.J. Williams, Glass transition temperature versus conversion relationships for thermosetting polymers, J. Polym. Sci. Part B: Polym. Phys. 28 (1990) 85-95, https://doi.org/10.1002/polb.1990.090280107.

[46] M. Romero, X. Fernández-Francos, X. Ramis, Sequential heat release: an innovative approach for the control of curing profiles during composite processing based on dual-curing systems, Polym. Int. 68 (2019) 527-545, https://doi.org/10.1002/pi. 5743.

[47] G. Wisanrakkit, J.K. Gillham, The glass transition temperature as a parameter for monitoring the isothermal cure of an amine-cured epoxy system, In: C.D. Craver, T. Provder (Eds.), Polymer Characterization, ACS Adv. Chem. Ser., Vol. 227, American Chemical Society, Washington, DC, 1990, pp. 143-166.

[48] A. Cadenato, J.M. Salla, X. Ramis, J.M. Morancho, L.M. Marroyo, J.L. Martin, Determination of gel and vitrification times of thermoset cruibg process by means of TMA, DMTA and DSC techniques TTT diagram, J. Therm. Anal. 49 (1997) 269-279.

[49] X. Fernández-Francos, W.D. Cook, J.M. Salla, À. Serra, X. Ramis, Crosslinking of mixtures of diglycidylether of bisphenol-A with 1,6-dioxaspiro[4.4] nonan-2,7-dione initiated by tertiary amines: III. Effect of hydroxyl groups on network formation, Polym. Int. 58 (2009) 1401-1410, https://doi.org/10.1002/pi. 2675 .

[50] C. Block, A.K. Ghosh, B. Van Mele, G. Van Assche, RheoDSC: design optimisation by heat transfer modelling, Thermochim. Acta 547 (2012) 130-140, https://doi. org/10.1016/j.tca.2012.08.019.

[51] I. Fraga, S. Montserrat, J.M. Hutchinson, Vitrification during the isothermal cure of thermosets. Part I. An investigation using TOPEM, a new temperature modulated technique, Thermal Anal. Cal. 91 (2008) 687-695, https://doi.org/10.1007/ s10973-007-8613-7 